\title{
CARTA A PIETR LAVROVITCH LAVROV, DE FRIEDRICH ENGELS
}

\author{
uma discussão acerca dos limites do darwinismo
}

\section{LETTER TO PIETR LAVROVITCH LAVROV, FROM FRIEDRICH ENGELS \\ a discussion about the limits of Darwinism}

Rafael Ferreira Martins ${ }^{1}$

(rafaelferreiramartins98@gmail.com)

\begin{abstract}
RESUMO
O socialismo e a luta pela existência, artigo do filósofo russo Pietr Lavrovitch Lavrov, abordara ideias darwinistas - centralizando-as na luta pela existência - sob um patamar social, isto é, adaptando e transpondo a tese exposta por Darwin em A origem das espécies do nível biológico para o nível social, com o importante acréscimo do conceito de solidariedade humana. Respondendo a seu artigo, Engels escreveu ao autor russo em 1875, por carta, suas refutações ao darwinismo social. O trabalho aqui apresentado resenha explicativa e criticamente a carta de Engels a Lavrov, explanando as refutações e problematizações apresentadas por Engels à implementação do darwinismo social na perspectiva materialista histórica por ele defendida. A argumentação de Engels pauta o nível biológico, da incompletude do darwinismo em si; o nível social, da falta de evidências nesse nível específico; e, por fim, o metafísico, da impossibilidade de transposição de uma tese de natureza biológica ao âmbito social.
\end{abstract}

Palavras-chave: Darwinismo social. Cooperacionismo. Materialismo.

\begin{abstract}
Socialism and struggle for existence, article written by the Russian philosopher Pietro Lavrovitch Lavrov, addressed Darwinian ideas, centering them on the struggle for existence, under a social level, that is, transposing and adapting Darwin's thesis, exposed in The origin of species, from the biological to the social level, with the important increase of the concept of human solidarity. Responding to Lavrov's article, Engels writes to the Russian author in a letter, in 1875, his refutations to social Darwinism. This paper reviews, in a critical and explanatory way, Engels' letter to Lavrov, explaining the refutations and problematizations presented by Engels to the implementation of social Darwinism in the historical materialist perspective. Engels arguments cover the biological level, concerning the incompleteness of Darwinism itself; the social level, on the lack of evidence at this specific level; and, finally, the metaphysical, on the impossibility of transposing a thesis from a biological to a social sphere.
\end{abstract}

Key-words: Social Darwinism. Cooperationism. Materialism.

\footnotetext{
1 Graduando em Filosofia pela Universidade de Brasília (UnB) e graduando em Física pela Universidade Paulista (UNIP).

CV Lattes: http://lattes.cnpq.br/9397082137728466.
} 
A Carta a Pietr Lavrovitch Lavrov foi escrita por Friedrich Engels no ano de 1875, especificamente no dia 12 de novembro, sofrendo interrupção por motivos pessoais de seu autor, com o retorno a sua escrita para finalização somente no dia 17 de novembro do mesmo ano. A carta foi escrita por Engels logo após seu regresso a Londres, no dia 6 de novembro de 1875, após uma viagem à Alemanha.

Em um âmbito geral, a carta se insere no período da vida acadêmica de Engels em que este acompanhava Marx no que ficou conhecido como o período da maturidade de Marx; em um âmbito específico, Engels estava publicando sua obra Do social na Rússia. A carta é uma resposta ao artigo $O$ socialismo e a luta pela existência, endereçada diretamente a seu autor, o filósofo e sociólogo russo Pietr Lavrovitch Lavrov.

Lavrov era um expoente teórico do narodismo (populismo russo) e publicara o artigo em questão tratando dos paralelos e embates entre a luta pela existência darwinista, no sentido biológico, e a luta pela existência socialista, no sentido histórico-social. Desde a polêmica publicação de A origem das espécies, de Charles Darwin, o uso da mentalidade e das conclusões expostas por Darwin com fins biológicos havia se transferido fortemente para fins sociais e históricos com grande repercussão, principalmente entre os teóricos materialistas socialistas.

$\mathrm{Na}$ carta de resposta a Lavrov argumentando sobre o artigo $O$ socialismo e a luta pela existência, Engels divide sua escrita em seis parágrafos pontuados para tratar de tópicos específicos. A língua escolhida para tal argumentação é o alemão, que, segundo Engels, é mais conciso do que o francês que utilizavam em tais cartas usualmente; inclusive, o autor inicia sua carta em francês, com o parágrafo de apresentação, e então justifica sua passagem para o alemão dali em diante.

A carta é iniciada, no primeiro parágrafo argumentativo, com a abordagem do darwinismo propriamente dito, isto é, em seu ambiente natural, a biologia. O desenvolvimento das espécies da teoria de Darwin é apresentado como aceitável, porém seu centro operacional, que Engels classifica como método de prova - o desenvolvimento e a manutenção ou extinção das espécies por meio da seleção natural (natural selection), da luta pela vida (struggle for life) -, é visto como provisório, algo que na visão de Engels ainda haveria de ser complementado. A complementação sobre a qual se expressa Engels faz referência à questão de a teoria darwinista ser simplista, reduzindo demasiadamente a dinâmica natural à luta pela existência (Kampf ums Dasein). Mais à frente, no final do primeiro parágrafo, Engels defende que aquilo que apresenta Darwin é aceitável cum grano salis (“com um grão de sal", com um complemento, isto é, somando-se a um todo). 
Engels demonstra que duas visões de mundo pós-Darwin estavam claras naquele momento: aqueles que apoiavam a visão cooperacionista da natureza, embasados no pensamento de Justus von Liebig (químico alemão que falecera dois anos antes de a carta em questão ser redigida), e aqueles que, fazendo uso extremista da tese darwinista, possuíam uma visão competitiva da natureza, "gente que agora só vê luta por toda parte" (ENGELS, 1875, $\S 1$, como especifica Engels. O autor ressalta, porém, que um desses grupos possui notória maioria naquele período, e esse grupo é o darwinista. Ambas as posições são, para o autor, limitadas, unilaterais e estreitas; o que uma tem em demasia a outra tem em nulidade. Engels, então, apresenta uma visão avançada de ecologia evolutiva, defendendo certa fusão entre as teses; ou seja, a dinâmica natural não se daria só pela seleção natural, na dimensão da luta pela existência, nem só pela cooperação entre os membros e sistemas naturais, mas sim como uma complexa malha de harmonia e colisão. A partir de tal posicionamento é realizado o salto do nível biológico para o nível histórico-social, criticando-se aqueles que, em seu naturalismo darwinista, "tentam subsumir toda a variada riqueza do desenvolvimento histórico na frase, unilateral e magra: luta pela existência" (ENGELS, 1875, §1).

O segundo tópico serve de plataforma para tratar de três autores utilizados no artigo de Lavrov (Seidlitz, Byr e Hellwald), autores aos quais Engels se refere como darwinistas convencidos (ubèzdennyie Darwinisty). Assim, Engels critica Georg Karl Maria Seidlitz, professor de Zoologia dos anos de ouro da Universität Dorpat, por ser pouco expressivo, apesar de não negativo; critica Robert Byr, classificando-o como simplesmente um romancista, com pensamentos fora da realidade, que só se enquadrariam em sua própria obra fíctícia; e, quanto a Friedrich von Hellwald, geógrafo e historiador austríaco, Engels o aponta como o único dos três autores que merece real menção.

Ao iniciar o terceiro tópico, o autor define o método de seu interlocutor, Lavrov, como psicológico, constatando que teria escolhido outro; porém, ressalva que Lavrov conhece melhor seu público, a Rússia. Com relação à Alemanha, Engels argumenta que tal método não seria bem aplicado, visto que o falso sentimentalismo que ali havia se instalado transformaria erroneamente o método de ataque de Lavrov em um modelo sentimentalista. O idealismo alemão é colocado como culpado de origem para a visão alemã da época, devendo, segundo Engels, ser abandonado para ser possível "estabelecer os factos materiais no seu direito histórico" (ENGELS, 1875, §3).

Ainda no terceiro tópico, é realizado um ataque teórico ao darwinismo burguês. Tal ataque consiste na suposição de que a doutrina darwinista da luta pela existência nada mais seria do que a manipulação e soma de três teorias anteriores: a 
teoria hobbesiana do bellum omnium contra omnes (guerra de todos contra todos), a teoria burguesa da concorrência e a teoria demográfica de Thomas Malthus. Ou seja, em essência, isto é, no que se refere à justificação da ocorrência da luta pela existência, o darwinismo burguês não teria feito nada mais do que transpor o raciocínio de Thomas Hobbes da luta de todos contra todos do patamar social para o biológico. Em ocorrência, isto é, da maneira como se desenrola o processo, o darwinismo burguês teria transferido a ideia de concorrência mercadológica para a concorrência ecológica. Por fim, em delimitação, isto é, no fator que limita e direciona o potencial da essência (luta de todos contra todos) e da intensidade da ocorrência (concorrência), encontra-se uma aplicação forçada da teoria da população de Thomas Malthus. Enfim, Engels é incisivo ao declarar como inválida a prática de transferir uma teoria natural para um objeto social, ou o inverso, pois a validade de uma teoria em relação ao patamar biológico não lhe concede pré-validação no nível social, uma vez que a natureza do objeto foi alterada.

Ao determinar, no tópico terceiro, a impossibilidade de simplesmente se transporem pensamentos concernentes ao meio social humano para o meio animal, o autor constrói o quarto tópico de maneira a explanar as diferenças centrais entre os homens e os outros animais. Engels defende que "a diferença essencial da sociedade humana relativamente à sociedade animal é que os animais, no máximo, recolhem [sammeln], enquanto os homens produzem" (ENGELS, 1875, §4). Essa diferença essencial por si só torna impossível a transposição clara entre o universo animal e o universo humano, pois o resultado do humano como produtor será um humano que, conforme desenvolve sua produção, torna mais escassa sua necessidade vital indispensável, criando assim novas necessidades, não mais como os animais (para sobreviver), mas sim como indivíduos sociais, com necessidades de prazer, por luxo. Assim, o ser humano, devido à sua natureza de produtor, foge da simples luta pela existência (Kampf ums Dasein) ao sanar gradativamente suas necessidades vitais diretas por meio de sua capacidade técnica, adentrando uma luta pelos prazeres (Kampf um Genüsse), da qual os animais não podem participar.

Após a clarificação sobre a produção humana, Engels explica que, sendo a produção capitalista muito maior do que é possível consumir e estando a massa produtora artificialmente afastada dos meios de desenvolvimento técnico e social, não é possível, para essa sociedade, tratar da luta pela existência. $\mathrm{O}$ autor defende, assim, que a estrutura social do capitalismo, por sua artificialidade e elevada geração de necessidades de luxo, por sua extravagante produção, não se encontra no nível básico da luta pela existência, mas sim no nível social da luta de classes. Logo, a luta de classes não equivale à luta pela existência na tese 
apresentada por Engels em sua carta a Lavrov; as duas encontram-se em estágios processuais diferentes e são, também, de naturezas diferentes.

No quinto tópico, muito sucinto, é substancialmente defendida a argumentação de Lavrov em relação à solidariedade. Lavrov havia dissertado em seu artigo que a ideia de solidariedade coloca a humanidade como uma sociedade de irmãos e, além de facilitar seu próprio combate, coloca-a em oposição à realidade mineral, vegetal e animal.

O último parágrafo argumentativo, o tópico sexto, é um contra-argumento à colocação da luta de todos contra todos como fase primordial do desenvolvimento humano, defendida por Lavrov. Engels opõe-se a Lavrov com a explicação de que o instinto social foi uma alavanca essencial do desenvolvimento humano e, sem ele, não poderíamos ter iniciado a vida em bando. Refuta Lavrov, enfim, ao expor que, tão longe quanto é possível remontar a história, não encontramos a luta de todos contra todos, somente vida em bando.

Em seu parágrafo de despedida, Engels admite que gostaria de mudar muitas palavras em seu manuscrito, mas que não o fez por receio de tornar seu trabalho ilegível. Alerta, também, que em sua dissertação teve maior apreço por tratar do método de ataque e da forma da teoria de Lavrov do que por tratar do plano de fundo de seu pensamento como um todo. 


\section{REFERÊNCIAS}

ENGELS, Friedrich; MARX, Karl. Carta a Pietr Lavrovitch Lavrov [ENGELS, Friedrich, 1875]. In: BARATA-MOURA, J.; CHITAS, E.; MELO, F.; PINA, A. Tradução José Barata-Moura. Obras escolhidas: Marx, Engels. Lisboa: Editorial Avante, 1982. 